\title{
Cloning and Selective Expression in Brain and Kidney of ARNT2 Homologous to the Ah Receptor Nuclear Translocator (ARNT)
}

\author{
Guillaume Drutel, ${ }^{* 1}$ Markus Kathmann, ${ }^{*}$ Anne Heron, $\dagger$ Jean-Charles \\ Schwartz,* and Jean-Michel Arrang*
}

*Unite' de Neurobiologie et Pharmacologie (U.109) de l'INSERM, Centre Paul Broca, 2ter rue d'Ale'sia, 75014 Paris, France; and $\dagger$ Laboratoire de Physiologie, Faculte’ de Pharmacie, Universite' Rene' Descartes, Paris, France

${ }^{1}$ To whom correspondence should be addressed.

\begin{abstract}
Arnt2, a new member of the basic-helix-loop-helix transcription factor family, was cloned from rat brain cDNAs. Its deduced 712 amino acid sequence displays $63 \%$ identity with that of the aryl hydrocarbon receptor nuclear translocator (Arnt1) that was completely established. Whereas Arnt2 gene expression, established by Northern blotting and in situ hybridization histochemistry, occurred selectively in brain and kidney, that of Arnt1 was ubiquitous, suggesting that the two proteins play distinct roles, presumably via dimerization and DNA binding with different partners.
\end{abstract}

Arnt, the Ah receptor nuclear translocator, is a member of the basic helix-loop-helix (bHLH) superfamily of DNA binding proteins, originally found to form a heterodimer with the aryl hydrocarbon receptor (Ahr) in response to environmental pollutants such as dioxins. The Ahr/Arnt heteromer translocates to the nucleus and binds specific recognition sequences localized upstream of various dioxin-inducible genes such as cytochromes P450 [reviewed in refs. 1-3].

Arnt sequence contains a conserved region termed the PAS domain and shared by other transcription factors [4]. Recent observations suggest that Arnt might have regulatory roles via heterodimerization not only with Ahr but also with other bHLH-containing PAS partners such as the single-minded protein (Sim), involved in central nervous system development $[5,6]$ and the hypoxia-inducible factor $1 a(\mathrm{HIF}-1 a)$ involved in adaptive responses of various cells and tissues to hypoxia [7].

Following RTPCR amplification of cerebral mRNAs using degenerate amplimers of heptahelical receptors, we unexpectedly cloned a cDNA of unknown sequence displaying however distinct homology with that of human or mouse Arnt (called Arnt1 here) [4, 8]. Here we report the full length sequence of this novel protein (designated Arnt2) as well as that of rat Arnt1, of which only a fraction was previously reported [9]. The latter was established for purpose of comparison and in order to design selective hybridization probes. Northern blot and in situ hybridization studies indicate that the two homologous gene transcripts are differently distributed among rat tissues. Recently, while this manuscript was in preparation, the sequence and properties of a mouse Arnt2 were disclosed [10]. 


\section{MATERIALS AND METHODS}

Cloning and sequencing of a rat Arnt 2 cDNA. A single strand cDNA was synthesized using AMV-reverse transcriptase (20 units, Boehringer) and rat frontal cortex poly(A) $\mathrm{mRNAs}(1 \mathrm{mg})$. This template was amplified for 35 cycles (947C, 507C and 727C for 1, 1 and 3 min, respectively) using Taq polymerase (2,5 units, Cetus) and two degenerate oligonucleotides based on the sequence of the third and sixth transmembrane domains of heptahelical receptors [11]. Sense $\left(5^{*}\right.$ CCCAAGCTTAAGTAGGG(CA)A(GA)CCAGCA(GTC)AI(GA)A(GT)GAA-3*) and anti-sense $\left(5^{*}\right.$-CCCAAGCTTCT(CG)TT(CT)(AG)T(CG)AT(CT)AGIIT(GT)GA(CT)(CA)GCG-3pr)

primers were synthesized with HindIII restriction sites at their $5^{*}$ ends. PCR products were cloned into pGEM 4Z (Promega) and sequenced by the dideoxy nucleotide chain termination method [12] with Sequenase version 2.0 (United States, Biochemical Inc.). Unexpectedly, one clone (A31) contained a $0.75 \mathrm{~kb}$ fragment which displayed significant homology with the PAS domain of the human and mouse Arnt1 [4, 8]. Therefore, the corresponding protein was designated Arnt2.

To obtain a full length Arnt2 sequence, a rat hypothalamus cDNA library constructed in $l$ ZapII was screened $\left(10^{6}\right.$ phages) at high stringency with a ${ }^{32} \mathrm{P}$-labelled DNA fragment corresponding to A31. Among 24 positive clones, one exhibited an open reading frame encoding a protein of 712 amino acids.

Cloning and sequencing of a full-length rat Arnt1 cDNA. A single strand cDNA was synthesized using AMVreverse transcriptase (20 units, Boehringer) and rat stomach poly(A)' mRNAs (1 mg). This template was amplified for 35 cycles (947C, 567C and 727C for 1, 1 and 2 min, respectively) using the Expand high fidelity PCR system (Boehringer) and two primers derived from the $5^{*}$ and $3^{*}$ non coding sequences of the human Arnt1 [4]. The sense $\left(5^{*}\right.$ GGTGGCGCGGCGGCGGTGGCATCA-3*) and antisense (5*CCTTATCCTCACCCCAATAGTTCT- $3^{*}$ ) primers corresponded to nucleotides 27 to 50 and 2426 to 2448 respectively. The amplified DNA was subcloned into pGEM 4Z and sequenced.

Northern blotting. Poly $(\mathrm{A})^{\prime}$ mRNAs $(8 \mathrm{mg})$ from various tissues of adult male Wistar rats were denaturated, electrophoresed and transferred to nitrocellulose membranes as described [13]. Hybridization was carried out overnight at $427 \mathrm{C}$ with probes ${ }^{32} \mathrm{P}$-labelled by random priming and corresponding to fragments of the rat Arnt1 or Arnt2 sequence (amino acids (a.a) 153 to 374 and 195 to 433 respectively) (Fig.1). Blots were washed twice in $21 \mathrm{SSC} / 0.1 \%$ SDS at 427C for 30 min and once in $0.21 \mathrm{SSC} / 0.1 \% \mathrm{SDS}$ at $427 \mathrm{C}$ for $30 \mathrm{~min}$. They were then exposed to X-ray films at $0807 \mathrm{C}$ for 21 days.

In situ hybridization. Cryostat sections $(12 \mathrm{~mm})$ of 4-day old rats were treated essentially as described [14]. The sections were hybridized in the presence of 50\% formamide and $6110^{6} \mathrm{dpm}$ antisense or sense RNA probes at 507C (Arnt1) or 557C (Arnt1). The highly variable C-terminal coding and non coding nucleotide sequences of rat Arnt1 or Arnt2 were used as probes for hybridization experiments. The probe corresponded to a.a. 683 to 796 for Arnt1. A $0.39 \mathrm{~kb}$ probe corresponding to the nucleotide sequence encoding from a.a. 608 and encompassing a part of the $3^{*}$ non coding sequence was used for Arnt2. After subcloning into pGEM 4Z, antisense and sense-

strand ${ }^{33} \mathrm{P}$-labeled probes were synthesized in vitro using SP6 or $\mathrm{T}_{7}$ RNA polymerase of Riboprobe kit (Promega).

\section{RESULTS}

Deduced amino acid sequences of rat Arnt1 and Arnt2. The full length cDNA sequence of rat Arnt 2 derived from degenerate PCR and brain cDNA library screening presented an open reading 
frame (ORF) encoding a protein of 712 aminoacids (Fig.1). This ORF starts by an ATG codon, the most upstream of a series of ATG codons and surrounded by 7 out of 10 nucleotides belonging to a consensus initiation sequence [15]. This sequence displayed high degrees of homology with those of full length human Arnt1 [4] and the partial sequence of rat Arnt1 [9]. We also cloned and sequenced a full length rat Arnt1 using PCR with primers designed in highly conserved regions of the human Arnt1. Two kinds of PCR products were obtained with ORFs encoding proteins of either 785 or 800 amino acids, presumably depending on the presence or absence of an alternative exon (sequence underlined in Fig.1). Arnt1 and Arnt2 sequences display a 63\% identity overall, a value increased to $75 \%$ and $95 \%$ considering the conserved PAS and bHLH domains respectively. The C-terminal end of sequences, following the PAS domain, displayed only $45 \%$ identity and a glutamine-rich region was present in both, although much longer in rArnt1 than in rArnt2 (Fig.1), mArnt1 or hArnt1 [4, 8].

Analysis of the sequences by the PROSITE program [16] showed 1, 9 and 8 consensus phosphorylation sites for protein kinases $\mathrm{A}$ and $\mathrm{C}$ and casein kinase II respectively in Arnt2 whereas corresponding values for Arnt 1 were 1, 10 and 16 respectively. Protein kinase C sites were absent from the hHLH domains of rArnt 1 and rArnt 2 whereas they occur in this domain of human AhR [17].

Analysis of Arntl and Arnt 2 gene expression in rat tissues. Northern blot analysis of Poly(A) ${ }^{\prime}$ mRNAs from rat tissues indicated the presence of a major 4.8-kb Arnt1 mRNA, highly expressed in adrenals, kidney, stomach and lung; lower signals were also detected in cerebral cortex and heart (Fig. 2).

Analysis of the same blot using a probe for rat Arnt2 mRNAs indicated the presence of a 7-kb transcript, highly expressed in cerebral cortex and kidney. A lower signal of the 7-kb transcript was detected in the stomach, a 6.7-kb Arnt 2 mRNA in the lung and no signals in adrenals and heart (Fig.2).

The distribution of Arnt1 and Arnt2 gene transcripts was studied further by in situ hybridization analysis performed on sagittal sections of newborn rats with an antisense RNA probe prepared in a specific (C-terminal) part of the Arnt1 or Arnt2 sequences. When compared with the corresponding sense probes for which no background signals could be seen (data not shown), the Arnt1- and Arnt2-antisense riboprobes generated clear signals (Fig.3). The Arnt1 gene was expressed in many (if not all) tissues. The highest expression level occured in the kidney, adrenals, intestine, spleen, salivary glands and retina. Signals could also be easily detected in the thymus, stomach, lung, brain and skin. Lower signals were found in many other tissues such as the heart and liver. The expression pattern of Arnt 2 was very different from that of Arnt1, with a highly discrete distribution of transcripts. High signals were found only in the brain, spinal cord (data not shown), sympathetic and spinal ganglia and kidney. In the latter, Arnt2 was highly expressed both in the external cortex and medulla. Lower signals were also found in the retina (Fig.3). 
rAInt2 MATPAAVNPPEMASDIPG-SVTLPVAPMAATGQVRMAGAMPARGGKRRSGMDFDDEDGEGPS-----rAInt1 MAATTAN--PEMTSDVPSLGPTIASGNPGPGIQG--GGAVVQRAIRRRSGLDFDDEGEVNSKFLRCDDEQ

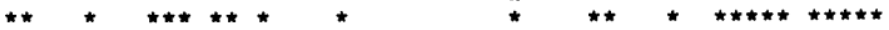

Basic Helix I LOOP Helix II

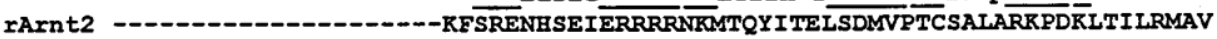
rAInt1 MCNDKERFARSDDEQSSADKERLARENHSEIERRRRNKMTAYITELSDMVPTCSALARKPDRLTIIRMAV

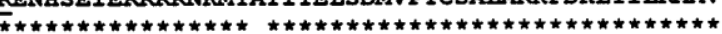

rArnt2 SHMRSMRGTGNRSTDGAYRPSFLTEQELKHLILEAADGFLFVVAAETGRVIYVSDSVTPVLNQPQSEWFG rAInt 1 SHMRSLRGTGNTSTDGSYRPSFLTDQELKHLI LEAADGFLFIVSCETGRVVYVSDSVTPVLNQPQSEWEG

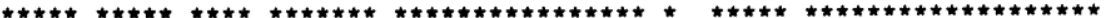

rArnt2 STLYEQVHPDDVERLREQLCTSENSMTGRILDIRTGTVKKEGQQSSMRMCMGSRRSFICRMRCGNAPLDH rAInT1 STLYDQVHPDDVDKIREQLSTSENALTGRILDLRTGTVKKEGQQSSMRMCMGSRRSFICRMRCGTSSVDP

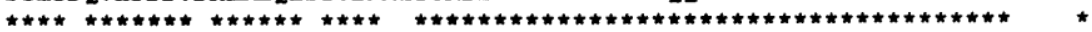

rAInt2 LPINRITTMRKRFRNGLGPVKEGEAQYAVVHCTGYIRAWPPAGMSIPEEDADVGQGSKYCLVAIGRLQVT rARnt1 VSMNRLSFLRNRCRNGLGSVKEGEPHFVVVHCTGYIKAWPPAGVSLPDDDPEAGQGSKFCLVAIGRLQVT

PAS B Region

rArnt2 SSPVCMDMSGMSVPTEFLSRHNSDGI ITFVDPRCISVIGYQPQDLLGKDII $\overline{\text { EFCHPEDQSHLRESFQQVV }}$ rArnt 1 SSPNCTDMSNICQPTEFISRHNIEGI FTEVDHRCVATVGYQPQELLGKNIVEFCHPEDQQLIRDSFQQVV $\star \star \star \star \star \star \star \star$

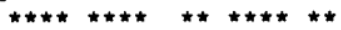

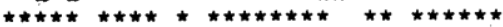

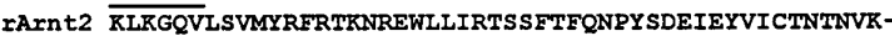

rAInt1 KLRGQVLSVMFRFRAKNREWLWMRTS STFQNPY SDEMS I FICTNTNVKNS SQEPRPTLSNTIQRSQLGP

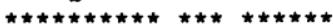

rArnt2 -QLQQQQAELE-VHQRDGLSSYDLSQVPVPNLPTGVHEAGRPVER rAInt1 TTNLSLEMGTGVIAASRQQQQQQQQQQQQQQQQTELDMVPGRDGLASYSHSQVSVQPVATAGSEHSKPLEK

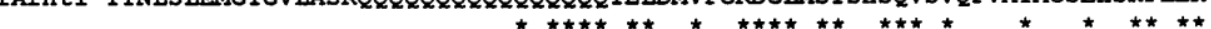

rArnt2 ADAIFSQERDPRFAEMFAGISASEKKMMSSASASGSQQIYSQGSPFPAGHSGKAFSSSVVHVPGVNDIQS rAInt1 SEGLFVQDRDPRFSEIYPNISADQSKGLSSSTVRATQQLFSQGSSFPPNPRPAENERNSGLTPPVTIVQP

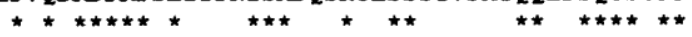

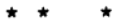

rArnt2 SSSTGQNISQISRQLNQGQVAW----TGSRPPFPGQP---SKTQSSAFGIGSSHPYPADPSSYSPLSSPA rArnt1 SSSAGQILAQISRHSNLTQGSAPTWTSSTRPGESAQLPTQATARTRSSQFGVNNFQTSSSFSAMSLPGAP

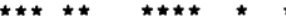

rArnt2 ASSPSGNAYPSLANRTPGFA-ESGQSGGQFQGRPSE---VWSQWQSQ--HHGQQSGEQHSH----QQPGQ rArnt 1 TASPSTAAYPTLPNRGSNFPPETGQTTGQFQTRTAEGVGVWPQWQGQQPHHRSSSNEQHVQPTSAQPSSQ

rArnt2 TEVFQDMLPMPGDPTQGTGNYNIEDFADLGMFPPFSE 712

rARnt1 PEVFQEMLSMLGDQSNT---YNNEEFPDLTMFPRESE 800

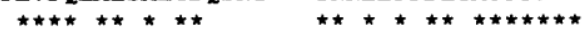

FIG. 1. Amino acid sequences of rat Arnt1 and Arnt2. Alignment was done by the program TREEALIGN of Hein et al.

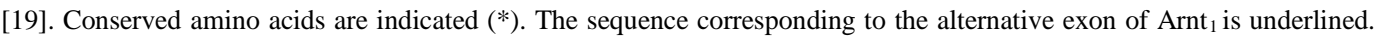
Dashed lines indicate gaps inserted to improve alignment. The nucleotide sequence of the Arnt 1 and Arnt 2 clones has been submitted to the GenBank data base with accession numbers U61184 and U61405, respectively. 
Arnt1

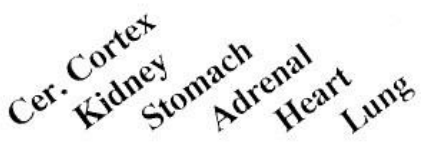

$7.5-$

$4.4-$

$2.4-$

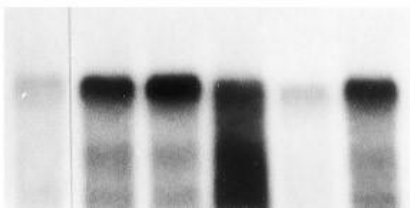

Arnt2

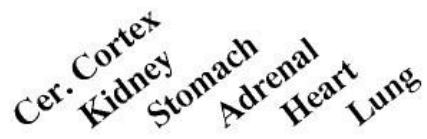

$7.5-$

$4.4-$

$2.4-$

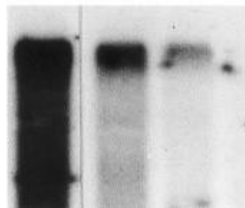

FIG. 2. Northern blot analysis. Poly $(\mathrm{A})^{\prime}$ mRNAs $(8 \mathrm{mg})$ from adult rat tissues were used. The blot was hybridized first with the $0.72-\mathrm{kb}$ Arnt 2 cDNA probe, and then dehybridized before hybridization with the 0.71-kb Arnt 1 probe. As a control, the blot was finally rehybridized with a $b$-actin cDNA which showed similar signals and minimal degradation in all samples (not shown). Blots were exposed for 21 days at $0807 \mathrm{C}$ with intensifying screens. The 0.24 to $9.5 \mathrm{~kb}$ RNA ladder was used for size markers, on the left. Cer. Cortex, cerebral cortex.

\section{DISCUSSION}

The sequence of the rat Arnt2 protein that we disclose here indicates that Arnt2 represents a new member of the bHLH-PAS family of transcription factors. Analysis of the bHLH and PAS domains revealed that Arnt2 is most similar to rat Arnt ${ }_{1}$ than to any other member of this family (Fig.1) suggesting that Arnt2 functions, like Arnt1, as a nuclear translocator. The high homology (95\% and $75 \%$ identity, respectively) found within the two domains suggests that Arnt1 and Arnt2 interact with the same partners (through the HLH and PAS motifs) and DNA recognition sequences (through the DNA binding (b) motif). The 15 a.a. sequence encoded by an alternative exon within the $\mathrm{N}$ terminal part of Arnt1 ([4] and Fig.1) and identifying two isoforms of this protein was not found in the corresponding sequence of Arnt2. However the putative existence of alternative exons in Arnt2 remains to be assessed by additional studies. The C-terminal sequence of both proteins beyond the PAS region is quite variable, with a remarkable Gln repeat (16 residues) found in the Q-rich region of Arnt1 but a shorter one in Arnt2, possibly indicating a different transcriptional activity of this region of the two (putative) translocators. In addition, Arnt1 and Arnt 2 sequences contain multiple but different consensus sites for protein kinases. Whether the respective phosphorylation of Arnt1 and Arnt2 proteins differentially affects the heterodimerization with their respective bHLHPAS partners remains to be elucidated [1]. 

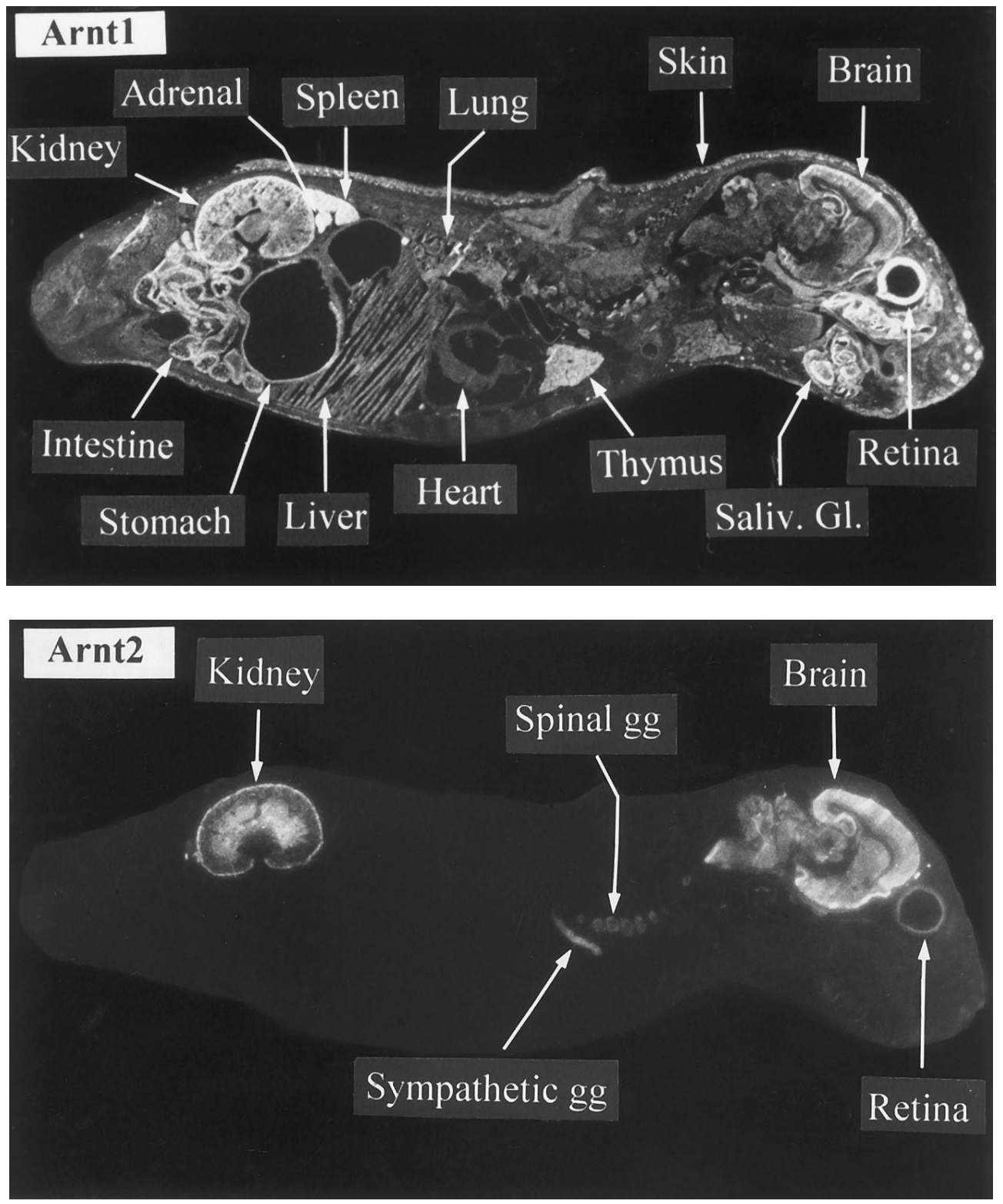

FIG. 3. In situ hybridization analysis. Sagittal sections of newborn (postnatal day 4) rats were hybridized with ${ }^{33}$ Plabelled antisense or sense riboprobes for Arnt 1 or Arnt 2 and exposed for 21 days. Note the restricted localization of Arnt 2 mRNAs in brain and kidney and the ubiquitous distribution of Arnt 1 mRNAs. Adjacent sections hybridized with a sense probe did not show any signal (not shown). The panels are dark-field photographs of autoradiograms. Saliv. Gl., Salivary gland; gg, ganglion.

Northern blot analysis showed different sizes for the transcripts of the two genes in rat tissues, i.e. $4.8 \mathrm{~kb}$ for Arnt 1 and $7.0 \mathrm{~kb}$ for Arnt2. In lung there was an additional Arnt2 mRNA of 6.7-kb which may correspond to the use of distinct initiation or polyadenylation sites or to a splice variant. 
In situ hybridization data of whole body sections of young rats, in agreement with data from Northern blot analysis, showed that the two genes are expressed in a markedly contrasted manner among rat tissues. Thus, Arnt1 gene is expressed in a highly ubiquitous manner in many peripheral organs as well as in selected regions of the central nervous system (hippocampus, cerebral and cerebellar cortices). This observation is consistent with data from Northern blot analysis and ribonuclease protection assays in selected rat or mice tissues [5,9] and with in situ hybridization histochemistry of rat brain [18]. Our data also point out to additional, previously non disclosed localisations of Arnt $1 \mathrm{mRNAs}$ such as in retina, adrenals or salivary glands.

In contrast, high expression of the Arnt2 gene was mainly restricted to the central and peripheral nervous system (brain, spinal cord, autonomic ganglia) and to the kidney (outer cortex and medulla).

All these data taken together strongly suggest that Arnt1 and Arnt2 play different physiological roles probably involving different partners.

While our work was progressing, Hirose et al. [10] reported the cloning of a mouse Arnt2, the amino acid sequence of which displays 99\% identity with that of rat Arnt2. In agreement with our data, mouse Arnt 2 was only expressed in the brain and kidney of adult mice when analyzed in northern blots, whereas the expression of Arnt1 was ubiquitous. In situ hybridization experiments with early mouse embryos in which AhR and Sim were previously shown to be expressed, also revealed a distinct expression pattern of Arnt1 and Arnt2.

\section{ACKNOWLEDGMENTS}

The authors thank Véronique Cochois for skilled technical assistance and Annie Galtier for typing the manuscript. Guillaume Drutel is a recipient of a fellowship from Association pour la Recherche sur le Cancer.

\section{REFERENCES}

1. Hankinson, O. (1995) Annu. Rev. Pharmacol. Toxicol. 35, 307-340.

2. Okey, A. B., Riddick, D. S., and Harper, P. A. (1994) Toxicology Letters 70, 1-22.

3. Swanson, H. I., and Bradfield, C. A. (1993) Pharmacogenetics 3, 213-230.

4. Hoffman, E. C., Reyes, H., Chu, F. F., Sander, F., Conley, L. H., Brooks, B. A., and Hankinson, O. (1991) Science 252, 954-958.

5. Ema, M., Suzuki, M., Morita, M., Hirose, K., Sogawa, K., Matsuda, Y., Gotoh, O., Saijoh, Y., Fujii, H., Hamada,H., and Fujii-Kuriyama, Y. (1996) Biochem. Biophys. Res. Comm. 218, 588-594.

6. Swanson, H. I., Chan, W. K., and Bradfield, C. A. (1995) J. Biol. Chem. 270, 26292-26302.

7. Wang, G. L., Jiang, B. H., Rue, E. A., and Semenza, G. L. (1995) Proc. Natl. Acad. Sci. USA 92, 5510-5514.

8. Li, H., Dong, L., and Whitlock, J. P., Jr. (1994) J. Biol. Chem. 269, 28098-28105.

9. Carver, L. A., Hogenesch, J. B., and Bradfield, C. A. (1994) Nucl. Acids Res. 22, 3038-3044.

10. Hirose, K., Morita, M., Ema, M., Mimura, J., Hamada, H., Fujii, H., Saijo, Y., Gotoh, O., Sogawa, K., and FujiiKuriyama, Y. (1996) Mol. Cell. Biol. 16, 1706-1713.

11. Libert, F., Parmentier, M., Lefort, A., Dinsart, C., Van Sande, J., Maenhaut, C., Simons, M. J., Dumont, J. E.,and Vassart, G. (1989) Science 244, 569-572.

12. Sanger, F., Nicklen, S., and Coulson, A. R. (1977) Proc. Natl. Acad. Sci. USA 74, 5463-5467.

13. Traiffort, E., Ruat, M., Arrang, J. M., Leurs, R., Piomelli, D., and Schwartz, J. C. (1992) Proc. Natl. Acad. Sci. USA 89, 2649-2653.

14. Bouthenet, M. L., Souil, E., Martres, M. P., Sokoloff, P., Giros, B., and Schwartz, J. C. (1991) Brain Res. 564, 203219.

15. Kozak, M. (1987) Nucl. Acids Res. 15, 8125-8148.

16. Bairoch, A. (1991) Nucl. Acids Res. 19, 2241-2245.

17. Dolwick, K. M., Schmidt, J. V., Carver, L. A., Swanson, H. I., and Bradfield, C. A. (1993) Mol. Pharmacol 44, 911917.

18. Kainu, T., Gustafsson, J. A., and Pelto-Huikko, M. (1995) Neuroreport 6, 2557-2560.

19. Hein, J. (1989) Mol. Biol. Evol. 6, 649-668. 